\title{
The Czech Republic SimSmoke: The Effect of Tobacco Control Policies on Smoking Prevalence and Smoking Attributable Deaths in the Czech Republic
}

\author{
David T. Levy, ${ }^{1,2}$ Hana Ross, ${ }^{3}$ Alexandra Kmetova, ${ }^{4}$ Eva Kralikova, ${ }^{4}$ Michal Stoklosa, ${ }^{3}$ \\ and Kenneth Blackman ${ }^{2}$ \\ ${ }^{1}$ Department of Oncology, Georgetown University, Washington, DC 20007, USA \\ ${ }^{2}$ Pacific Institute for Research and Evaluation, Calverton, MD 20705, USA \\ ${ }^{3}$ International Tobacco Control Research, American Cancer Society, Atlanta, GA 30303, USA \\ ${ }^{4}$ Tobacco Dependence Treatment Centre, Charles University, Prague, Czech Republic
}

Correspondence should be addressed to David T. Levy, dl777@georgetown.edu

Received 4 January 2012; Accepted 24 January 2012

Academic Editors: W. Aekplakorn, J. U. Béria, and S. Siziya

Copyright (C) 2012 David T. Levy et al. This is an open access article distributed under the Creative Commons Attribution License, which permits unrestricted use, distribution, and reproduction in any medium, provided the original work is properly cited.

\begin{abstract}
Background. The Czech Republic has a weak tobacco control record. This paper describes a simulation model examining the effect of future tobacco control policies in the Czech Republic on smoking prevalence and associated future premature mortality. Methods. The model is developed using the SimSmoke simulation model of tobacco control policy. The model uses population, smoking rates and tobacco control policy data for the Czech Republic. It assesses, individually and in combination, the effect of taxes, smoke-free air laws, mass media campaigns, advertising bans, warning labels, cessation treatment, and youth access policies. Results. With a comprehensive set of policies, smoking prevalence can be reduced by as much as $22 \%$ in the first year, by $35 \%$ in 20 years, and up to $40 \%$ in 30 years. By 2040, 5,873 deaths can be averted in that year alone. Without these policies, 113,004 people in the Czech Republic will die prematurely in the next 30 years. Conclusions. The model shows that significant inroads to reducing smoking prevalence and premature mortality can be achieved through tax increases, a high intensity media campaign, a comprehensive cessation treatment program, strong health warnings, stronger smoke-free air laws and marketing bans, and well-enforced youth access laws.
\end{abstract}

\section{Introduction}

Globally, 5 million premature deaths each year are attributable to smoking [1]. Approximately, 18,000 of these deaths are in the Czech Republic (CR), a country in the heart of Europe with a population of 10 million [1]. To reduce this toll, the World Health Organization has set out the Framework Convention for Tobacco Control (FCTC). Substantial evidence indicates that higher cigarette taxes, clean air laws, advertising bans, and media campaigns can appreciably reduce adult smoking rates, especially when combined as a comprehensive strategy $[2,3]$. MPOWER [4] suggests specific policies consistent with the FCTC.

The CR has signed, but not yet ratified the FCTC, thus being the only country in the European Union not a party to the FCTC. The CR has a notably high rate of smoking $(35 \%$ of men and $27 \%$ of women smoke) [5], with policy makers openly supporting the tobacco industry [6]. Since 1995, the CR has increased cigarette taxes and strengthened health warnings in order to comply with EU regulations, but has done little else, and cigarette prices are still low relative to other EU nations and the local standard of living [7].

Since the ability of purely statistical studies to distinguish the effects of different policies on smoking rates is limited, simulation models combine information from different sources to provide a useful tool for examining how the effects of public policies unfold over time $[8,9]$. SimSmoke simultaneously considers a broader array of public policies than other models [10] and has been validated in several countries $[11,12]$ and US states [13-15]. 
A modified version of SimSmoke has been developed for the CR. Using CR data on population, birth rates, death rates, and smoking rates, the model predicts future smoking rates and the number of smoking-attributable deaths (SADs) in total and by age and gender. This paper uses SimSmoke to examine the effect of MPOWER policies in the CR.

\section{Methods}

SimSmoke includes population, smoking, SADs, and policy modules [9]. The model begins in a baseline year with the population divided into current, never, and former smokers by age and gender. The baseline year, 2002, is based on the availability of a large scale survey for that year and stability of policies during that period. A discrete time first-order Markov process is employed to project future population growth through fertility and deaths, and smoking rates through smoking initiation, cessation, and relapse. Smoking rates, and thereby SADs, change over time in response to changes in tobacco control policies.

2.1. Population Model. Population (2002), mortality (2001), and fertility (2001) data by age and gender are from the Statistical Office of the Czech Statistical Agency. Projections from the model through 2010 showed a slight decline in population, consistent with estimates from the World Factbook [16].

2.2. Smoking Model. Within the smoking model, individuals are classified as never smokers from birth until they initiate smoking or die. They may evolve from current to former smoker through cessation or may return to smoker through relapse. The extent of relapse depends on the number of years quit.

The 2002 data on smoking prevalence is from the Sample Survey of the Health Status of the Czech Population of UZIS (Institute of Health Information and Statistic), a nationally representative multistage cluster sample, interviewer administered questionnaire with a sample size of about 2,500 respondents 15 years and above. The survey is also available for 1995, 1999, 2005, and 2008. According to those surveys, the smoking rate dropped from 1995 to 1999 and was stable between 1999 and 2002 and relatively stable with a small decline between 2002 and 2005.

The UZIS interviewer asks "Do you smoke?" and asks those who answer "no" if they ever smoked. In the model, occasional and everyday smokers of any tobacco products are included as current smokers. However, since the sample was small, former smokers were distinguished by years quit using the Netherlands data from 1996, when their smoking rates (prior to major policies) were comparable to 2002 CR rates.

Due to empirical challenges in measuring initiation and cessation and in order to ensure internal consistency of the model, initiation rates at each age are measured as the difference between the smoking rate at that age year and the rate at the previous age year. Upon examining smoking rates in 2002 and earlier years, initiation was set to continue through age 30 for males and through age 35 for females.
In calibrating the model, smoking rates for ages 18-28 were examined to confirm our choice of maximum initiation age.

Data was not available for cessation rates. We initially chose a first year cessation rate of $4 \%$ and allowed $50 \%$ relapse, yielding rates consistent with estimates from Great Britain [17] and the Netherlands [18]. Because data were not available for the CR, we used US relapse rates $[19,20]$.

2.3. Smoking-Attributable Deaths. Death rates by age, gender, and smoking status were calculated from death rates, smoking rates, and relative risks. The number of current and former smokers at each age was multiplied by their respective excess risk and summed to obtain total SADs.

Large-scale studies of smoking risk were not available for the CR. Because the CR is a high income nation with a similar smoking history to the US, we use relative risk estimates from the US Cancer Prevention Study II [21]. Similar risks have been found for Great Britain [22] and for post-transition Russia [23]. For exsmokers, relative risks were assumed to decline at rates observed in US studies [21].

2.4. Policies. Policy effect sizes are in terms of percentage reductions applied to smoking prevalence in the year when a policy is implemented, and, unless otherwise specified, applied to initiation and cessation rates in future years. Policies and effect sizes are summarized in Table 1.

The effect of implementing a policy depends on the prior level of that policy. We input data on policy levels for each year from 2002 through 2010 based on MPOWER reports [4] and information provided by staff in the CR.

Tax policy in SimSmoke uses inflation-adjusted cigarette prices as the policy input through 2010, and uses the total cigarette excise (including ad valorem and specific) tax to adjust future prices. A cigarette price index (measured with a 0.5 weight each to a local brand and Marlboro) was obtained from the EIU [24], deflated by the CPI [25]. In future years, price increases in absolute terms by the amount of the cigarette tax increase per unit [26]. Based on information from the European Union, the excise tax rate in 2010 was $64 \%$. The MPOWER target-specific tax rate is $70 \%$ of the retail price, upon adjusting for their reduced percentage in overall price due to value added taxes. Changes in price are translated into changes in smoking prevalence through elasticities. A price elasticity estimate was not found for the CR, but estimates from Germany [27] are comparable to the US price elasticities of -0.3 for those through age $24,-0.2$ for ages $25-34$, and -0.1 for ages 35 and above are applied.

Smoke-free air policy considers smoking restrictions in: (1) worksites, (2) restaurants and bars, and (3) other places, with their effect dependent on enforcement and publicity (based on the level of tobacco control campaigns). No studies of the effect of smoke-free indoor air laws were found for the CR. We primarily rely on US studies, but also considered the CR's unemployment rate and the percent of the workers employed in agriculture $(<5 \%)$ [16]. With strong enforcement and publicity, the effect of a ban in restaurants was estimated as $2 \%$, in pubs and bars $1 \%$, in worksites $6 \%$, and in other public places $1 \%$, with the full effects dependent on enforcement [28]. The 1989 Tobacco Act gave limited 
Table 1: Policies, description, and effect sizes of the SimSmoke model.

\begin{tabular}{|c|c|c|}
\hline Policy & Description & Potential percentage effect* \\
\hline Tax Policy & $\begin{array}{l}\text { Cigarette price index, taxes measure in absolute } \\
\text { terms }\end{array}$ & $\begin{array}{l}\text { Through price elasticity: }-0.3 \text { ages } 15-24,-0.2 \text { ages } \\
25-34 \text { and }-0.1 \text { ages, } 35 \text { and above }\end{array}$ \\
\hline \multicolumn{3}{|l|}{ Smoke-Free air policies } \\
\hline Total worksite ban & Ban in all areas & $6 \%$ with variations by age and gender \\
\hline Weak worksite ban & Smoking limited to nonventilated common area & $2 \%$ with variations by age and gender \\
\hline Restaurant total ban & Ban in all indoor restaurants in all areas & $1 \%$ effect \\
\hline Other places total ban & $\begin{array}{l}\text { Ban in } 3 \text { of } 4 \text { (malls, retail stores, public } \\
\text { transportation, and elevators) }\end{array}$ & $1 \%$ effect \\
\hline Enforcement and publicity & $\begin{array}{l}\text { Government agency is designated to enforce and } \\
\text { publicize the laws }\end{array}$ & Effects reduced by $50 \%$ if 0 enforcement \\
\hline \multicolumn{3}{|l|}{ Mass media campaigns } \\
\hline Highly publicized campaign & $\begin{array}{l}\text { Campaign publicized heavily on TV (at least two } \\
\text { months of the year) and at least some other media }\end{array}$ & $\begin{array}{l}3.25 \% \text { effect (doubled when accompanied by other } \\
\text { policies) }\end{array}$ \\
\hline Low publicity campaign & $\begin{array}{l}\text { Campaign publicized only sporadically in } \\
\text { newspaper, billboard, or other media }\end{array}$ & $\begin{array}{l}0.5 \% \text { effect (doubled when accompanied by local } \\
\text { other policies) }\end{array}$ \\
\hline \multicolumn{3}{|l|}{ Marketing ban } \\
\hline Comprehensive marketing ban & $\begin{array}{l}\text { Ban is applied television, radio, print, billboard, } \\
\text { in-store displays, sponsorships, and free samples }\end{array}$ & $\begin{array}{l}5 \% \text { reduction in prevalence, } \\
6 \% \text { reduction in initiation, } \\
3 \% \text { increase in cessation rates }\end{array}$ \\
\hline Total Advertising Ban & $\begin{array}{l}\text { Ban is applied all media television, radio, print, } \\
\text { billboard }\end{array}$ & $\begin{array}{l}3 \% \text { reduction in prevalence, } \\
4 \% \text { reduction in initiation, } \\
2 \% \text { increase in cessation rates }\end{array}$ \\
\hline Enforcement and publicity & $\begin{array}{l}\text { Government agency is designated to enforce the } \\
\text { laws }\end{array}$ & Effects reduced by as much as $50 \%$ if 0 enforcement \\
\hline \multicolumn{3}{|l|}{ Warning labels } \\
\hline Strong & Labels are large, bold and graphic & $\begin{array}{l}2 \% \text { reduction in prevalence and initiation, } 4 \% \\
\text { increase in cessation }\end{array}$ \\
\hline Weak & $\begin{array}{l}\text { Laws cover less than } 1 / 3 \text { of package, not bold or } \\
\text { graphic }\end{array}$ & $\begin{array}{l}1 \% \text { reduction in prevalence and initiation, } 2 \% \\
\text { increase in cessation }\end{array}$ \\
\hline Publicity & Health information is well publicized & $\begin{array}{l}1 \% \text { additional effect on prevalence and initiation } \\
\text { rates }\end{array}$ \\
\hline Cessation treatment policy & $\begin{array}{l}\text { Complete availability and reimbursement of } \\
\text { pharmacological and behavioral treatments, } \\
\text { quitlines, and brief interventions }\end{array}$ & $\begin{array}{l}4.75 \% \text { reduction in prevalence, } 39 \% \text { increase in } \\
\text { cessation rate }\end{array}$ \\
\hline
\end{tabular}

\section{Youth Access Restrictions}

Strongly enforced \& publicized

Low enforcement
Regular compliance checks, heavy penalties, high visibility, vending machine and self-service bans

No compliance checks; weak penalties, and no publicity or bans
$30 \%$ reduction for age $<16$ in prevalence and initiation only, $20 \%$ reduction for ages $16-17$ in prevalence and initiation only

$3 \%$ reduction for age $<16$ in prevalence and initiation only, $2 \%$ reduction for ages $16-17$ in prevalence and initiation only

\footnotetext{
* Unless otherwise specified, the same percentage effect is applied as a percentage reduction in the prevalence and initiation rate and a percentage increase in the cessation rate, and is applied to all ages and both genders. The effect sizes are shown to be relative to the absence of any policy. They are based on literature reviews, advice of an expert panel, and model validation.
}

scope to smoke-free air laws (e.g., smoking ban in restaurants applied only for parts of the day without hours clearly specified). The Act was amended in 1999 to include smoke-free working places (within limited areas, for sport and culture facilities). The CR is considered to have a weak worksite ban, no ban in restaurants, pubs or bars, and a $50 \%$ ban in all other public places for all years. From MPOWER [4], the enforcement level is set to 4 (out of 10).
MPOWER [4] distinguishes enforcement and 3 levels of direct (advertising and point of sale) and indirect (sponsorships, branding, or promotional discounts) marketing bans: minimal, moderate, and complete. With a complete ban, prevalence is reduced by $5 \%$ and initiation by $6 \%$, and cessation is increased by $3 \%[3,29]$. Since 1995 , the CR has had a ban on television and radio advertising for certain hours, with some additional restrictions added in 2001. There are some 
limitations on sponsorship and branding, but no limitations on point of sale advertising. The level is set to 3 from 2002 to the present. Enforcement is set to 7 [4].

MPOWER provides 3 levels for health warnings: minimal $(<30 \%$ of the principal display area), moderate $(\geq 30 \%$ of display area and rotating) and strong ( $\geq 50 \%$ of the display area, rotating bold, graphic, and a ban on deceitful terms). Based on a review [3] and recent studies [30, 31], strong health warnings reduce prevalence by $2 \%$ and initiation by $1 \%$, and increases cessation by $5 \%$. When moderate (low), prevalence is reduced by $0.75 \%(0.5 \%)$, cessation is increased by $2.5 \%(1.0 \%)$ and initiation is reduced by $0.5 \%(0.5 \%)$, with an added impacted of tobacco control campaigns (an additional $1 \%$ reduction in prevalence and $2 \%$ increase in cessation). The CR had minimal health warnings from 1991 to 2003 , when they became moderate, covering $30 \%$ of one side of the box.

SimSmoke specifies three levels for tobacco control campaigns - low: a national agency and minimal funding or employees; medium: $10+$ employees or per capita expenditures over $\$ 0.10$ (USD) per capita; high: expenditures over $\$ 0.50$ (USD) per capita, and incorporates synergies from publicity surrounding other policies. Based on reviews [3, 32], a wellfunded tobacco control campaign in conjunction with other policies yields an effect size of $6.5 \%$, compared to an effect size of $1 \%$ for a low intensity campaign. MPOWER [4] does not provide expenditure data, but indicates the absence of a tobacco control agency. Czech staff indicated that there were sporadic campaigns. Tobacco control campaigns is set to low for all years

A strongly enforced policy restricting cigarette purchases by youth reduces smoking prevalence by those under age 18 by as much as $25 \%$ [33]. Since 1999 , the purchase of tobacco products by those under the age of 18 has been illegal. However, over $70 \%$ of $13-15$ years olds who attempted to buy cigarettes in a store were not refused purchase [34, 35]. Therefore, youth access enforcement is set to low, with no bans on vending machines or self-service displays.

Cessation treatment includes four subpolicies. Treatment coverage is based on the places providing cessation treatments. With publicity, prevalence is reduced by $2.25 \%$, and cessation rate increased by $12 \%$ [36]. The effect of a wellpublicized quitline reduces prevalence by $0.5 \%$ and increases cessation 5\% [36]. With bupropion available by prescription and NRT available over-the-counter, prevalence is reduced by $1.0 \%$, and cessation increased $6 \%[37,38]$. Brief interventions involves advice and assistance by health care providers, which reduces prevalence by up to $0.5 \%$, and increase cessation $10 \%$ [36]. With all subpolicies implemented, prevalence is reduced $4.75 \%$ and cessation increased $40 \%$.

Since at least 2002, NRT has been available in pharmacies, and bupropion has been available by prescription. Treatments are provided in some primary care facilities, hospitals, and offices of health professionals [4], with 30 centres providing treatment covered partly by national health insurance. These policies are assumed to have been in place since 2002, with community coverage beginning in 2007. A quitline has been operating since 2005, but is underfunded, operates limited hours and is not publicized. Doctors are not reimbursed for brief interventions, which, according to patients, are provided during less than $20 \%$ of visits [39] and is set to $20 \%$.

2.5. Model Outcomes. The model projects two primary outcomes over time: smoking prevalence and SADs. To calibrate the model, we compared trends in smoking prevalence from the model over the period from 1993 to 2002 to trends gleaned from UZIS surveys over the period 1993-2002. To validate the model, we compare projected smoking prevalence to trends from Sovinová et al. [40].

The effect of implementing MPOWER policies in 2011 is gauged relative to the status quo scenario, where tobacco control policies are maintained at their 2010 level. Results for smoking prevalence are presented in relative terms, that is, the difference in smoking prevalence from the status quo divided by status quo smoking prevalence. Lives saved are calculated as the difference in the number of SADs with the policy and under the status quo. We consider tobacco control policies in isolation and through a comprehensive strategy simultaneously implementing all policies.

\section{Results}

3.1. Smoking Prevalence from 2002 to 2010. Between 2002 and 2010, the model predicts that male smoking rates (as a percent of the population ages 15 and above) decrease from $37.3 \%$ to $34.6 \%$ (a $10 \%$ decrease in relative terms) and that female smoking rates remain almost constant, decreasing from $23.2 \%$ to $23.1 \%$. These predictions are consistent with survey data [40] that show that smoking rates have been slowly falling while female rates have stay stayed quite constant from 1999 to 2009. Like external data [40], the model predicts slow declines in smoking rates for all age groups, except the older ages where there is a slow increase.

\subsection{Future Policies to Reduce Smoking Prevalence and SADs.} Predicted smoking prevalence under the status quo and under varying policy scenarios are shown in Tables 2(a) and 2(b) for males and females, respectively. The total number of projected SADs for a specific year and the cumulative total for 2010-2040 are displayed in Table 3.

If tobacco control policies remain unchanged from their 2010 levels, as in the status quo scenario, male adult smoking is projected to fall from $34.6 \%$ in 2010 to $32.4 \%$ by 2020 , to $29.5 \%$ by 2030 , and to $27.5 \%$ by 2040 . In the status quo scenario, female smoking prevalence is projected to fall from $23.1 \%$ in 2010 to $22.7 \%$ by 2020 , to $21.3 \%$ by 2030 , and to $18.7 \%$ by 2040 . The estimated number of SADs in 2010 alone is 21,885 (16,110 males and 5,775 females). Male SADs are projected to increase until 2022, but then decline. Female SADs are 5,775 in 2010 and projected to increase by 3,122 per year by 2040 .

Relative to the status quo, increasing excise taxes to $70 \%$ of the current price is projected to reduce smoking prevalence in relative terms by $5.1 \%$ for males and $4.8 \%$ for females in 2011. By 2040, smoking prevalence is projected to decline by $9.9 \%$ for males $8.7 \%$ for females. With the $70 \%$ tax, 1,042 lives are saved in the year 2040. Summing over 
TABLE 2: (a) SimSmoke projections of male smoking prevalence for ages 15 and older, Czech Republic, 2010-2040. (b) SimSmoke projections of female smoking prevalence for ages 15 and older, Czech Republic, 2010-2040.

(a)

\begin{tabular}{|c|c|c|c|c|c|}
\hline Policy/year & 2010 & 2011 & 2020 & 2030 & 2040 \\
\hline Status quo policies & $34.6 \%$ & $34.4 \%$ & $32.4 \%$ & $29.9 \%$ & $27.5 \%$ \\
\hline \multicolumn{6}{|l|}{ Policies implemented in 2011} \\
\hline Tax at $70 \%$ of retail price & $34.6 \%$ & $32.7 \%$ & $30.3 \%$ & $27.4 \%$ & $24.7 \%$ \\
\hline Complete smoke free and enforcement & $34.6 \%$ & $32.1 \%$ & $30.1 \%$ & $27.5 \%$ & $25.1 \%$ \\
\hline Comprehensive Ad Ban and Enforcement & $34.6 \%$ & $33.6 \%$ & $31.6 \%$ & $29.0 \%$ & $26.5 \%$ \\
\hline High Intensity Tobacco Control Campaign & $34.6 \%$ & $32.5 \%$ & $30.4 \%$ & $27.8 \%$ & $25.4 \%$ \\
\hline Strong health warnings & $34.6 \%$ & $34.3 \%$ & $32.3 \%$ & $29.6 \%$ & $27.2 \%$ \\
\hline Strong youth access enforcement & $34.6 \%$ & $34.2 \%$ & $31.5 \%$ & $28.2 \%$ & $25.3 \%$ \\
\hline Cessation treatment policies & $34.6 \%$ & $33.6 \%$ & $31.0 \%$ & $28.2 \%$ & $25.7 \%$ \\
\hline All of the above & $34.6 \%$ & $26.9 \%$ & $23.1 \%$ & $19.4 \%$ & $16.4 \%$ \\
\hline \multicolumn{6}{|c|}{$\%$ Change in smoking prevalence from status quo } \\
\hline Tax at $70 \%$ of retail price & & $-5.1 \%$ & $-6.6 \%$ & $-8.3 \%$ & $-9.9 \%$ \\
\hline Complete smoke free and enforcement & & $-6.7 \%$ & $-7.3 \%$ & $-7.9 \%$ & $-8.5 \%$ \\
\hline Comprehensive Ad ban and enforcement & & $-2.4 \%$ & $-2.7 \%$ & $-3.0 \%$ & $-3.4 \%$ \\
\hline High intensity tobacco control campaign & & $-5.6 \%$ & $-6.3 \%$ & $-7.1 \%$ & $-7.7 \%$ \\
\hline Strong health warnings & & $-0.2 \%$ & $-0.6 \%$ & $-0.8 \%$ & $-1.0 \%$ \\
\hline Strong youth access enforcement & & $-0.5 \%$ & $-2.8 \%$ & $-5.4 \%$ & $-8.0 \%$ \\
\hline Cessation treatment policies & & $-2.3 \%$ & $-4.4 \%$ & $-5.7 \%$ & $-6.4 \%$ \\
\hline \multicolumn{6}{|l|}{ Combined policy effects } \\
\hline All of the above & & $-21.7 \%$ & $-28.9 \%$ & $-35.1 \%$ & $-40.1 \%$ \\
\hline
\end{tabular}

${ }^{*}$ Measured relative to the status quo in the same year, that is, $\left(\mathrm{SR}_{p, t}-\mathrm{SR}_{\text {Status quo, }, t}\right) / \mathrm{SR}_{\text {Status quo, },}$, where $\mathrm{SR}_{p, t}$ is the smoking rate in year $t$ with policy $p$ and $\mathrm{SR}_{\text {Status quo, } t}$ is the smoking rate in year $t$ under the status quo.

(b)

\begin{tabular}{|c|c|c|c|c|c|}
\hline Policy/year & 2010 & 2011 & 2020 & 2030 & 2040 \\
\hline Status quo policies & $23.1 \%$ & $23.2 \%$ & $22.7 \%$ & $21.4 \%$ & $19.8 \%$ \\
\hline \multicolumn{6}{|l|}{ Independent policies implemented in 2011} \\
\hline Tax at $70 \%$ of retail price & $23.1 \%$ & $22.1 \%$ & $21.4 \%$ & $19.8 \%$ & $18.0 \%$ \\
\hline Complete smoke free and enforcement & $23.1 \%$ & $21.6 \%$ & $21.1 \%$ & $19.7 \%$ & $18.1 \%$ \\
\hline Comprehensive Ad ban and enforcement & $23.1 \%$ & $22.6 \%$ & $22.1 \%$ & $20.7 \%$ & $19.1 \%$ \\
\hline High intensity tobacco control campaign & $23.1 \%$ & $21.9 \%$ & $21.3 \%$ & $19.9 \%$ & $18.3 \%$ \\
\hline Strong health warnings & $23.1 \%$ & $23.1 \%$ & $22.6 \%$ & $21.2 \%$ & $19.5 \%$ \\
\hline Strong youth access enforcement & $23.1 \%$ & $23.1 \%$ & $22.2 \%$ & $20.4 \%$ & $18.5 \%$ \\
\hline Cessation treatment policies & $23.1 \%$ & $22.6 \%$ & $21.7 \%$ & $20.1 \%$ & $18.4 \%$ \\
\hline All of the above & $23.1 \%$ & $18.2 \%$ & $16.3 \%$ & $14.2 \%$ & $12.2 \%$ \\
\hline \multicolumn{6}{|c|}{$\%$ Change in smoking prevalence from status quo } \\
\hline \multicolumn{6}{|l|}{ Independent policy effects } \\
\hline Tax at $70 \%$ of retail price & & $-4.8 \%$ & $-6.0 \%$ & $-7.4 \%$ & $-8.7 \%$ \\
\hline Complete smoke free and enforcement & & $-6.7 \%$ & $-7.3 \%$ & $-7.9 \%$ & $-8.4 \%$ \\
\hline Comprehensive Ad ban and enforcement & & $-2.4 \%$ & $-2.7 \%$ & $-3.0 \%$ & $-3.3 \%$ \\
\hline High intensity tobacco control campaign & & $-5.6 \%$ & $-6.4 \%$ & $-7.0 \%$ & $-7.6 \%$ \\
\hline Strong health warnings & & $-0.2 \%$ & $-0.6 \%$ & $-0.9 \%$ & $-1.1 \%$ \\
\hline Strong youth access enforcement & & $-0.4 \%$ & $-2.2 \%$ & $-4.3 \%$ & $-6.3 \%$ \\
\hline Cessation treatment policies & & $-2.3 \%$ & $-4.6 \%$ & $-6.0 \%$ & $-6.8 \%$ \\
\hline \multicolumn{6}{|l|}{ Combined policy effects } \\
\hline All of the above & & $-21.4 \%$ & $-28.1 \%$ & $-33.8 \%$ & $-38.1 \%$ \\
\hline
\end{tabular}

${ }^{*}$ Measured relative to the status quo in the same year, that is, $\left(\mathrm{SR}_{p, t}-\mathrm{SR}_{\text {Status quo, }, t}\right) / \mathrm{SR}_{\text {Status quo, },}$, where $\mathrm{SR}_{p, t}$ is the smoking rate in year $t$ with policy $p$ and $\mathrm{SR}_{\text {Status quo, } t}$ is the smoking rate in year $t$ under the status quo. 
TABLe 3: Smoking attributable deaths, Czech Republic, 2010-2040.

\begin{tabular}{|c|c|c|c|c|c|}
\hline Policy/year & 2010 & 2020 & 2030 & 2040 & Cumul. \\
\hline Status quo policies & 21,885 & 26,790 & 27,475 & 24,172 & 781,152 \\
\hline \multicolumn{6}{|l|}{ Independent policies implemented in 2010} \\
\hline Tax $70 \%$ of retail price (w/adjustment for VAT) & 21,885 & 26,407 & 26,568 & 23,130 & 762,144 \\
\hline Complete smoke free and enforcement & 21,885 & 26,071 & 25,895 & 22,627 & 748,629 \\
\hline Comprehensive Ad ban and enforcement & 21,885 & 26,535 & 26,925 & 23,643 & 769,805 \\
\hline High intensity tobacco control campaign & 21,885 & 26,183 & 26,099 & 22,786 & 752,840 \\
\hline Strong health warnings & 21,885 & 26,745 & 27,348 & 24,006 & 778,515 \\
\hline Strong youth access enforcement & 21,885 & 26,790 & 27,466 & 24,079 & 780,664 \\
\hline Cessation treatment policies & 21,885 & 26,383 & 26,366 & 22,796 & 758,275 \\
\hline All of the above & 21,885 & 24,462 & 22,001 & 18,297 & 668,130 \\
\hline \multicolumn{6}{|c|}{ Absolute change in attributable deaths from status quo (lives saved) } \\
\hline Tax $70 \%$ of retail price (w/adjustment for VAT) & & 383 & 907 & 1,042 & 19,008 \\
\hline Complete smoke free and enforcement & & 719 & 1,580 & 1,544 & 32,524 \\
\hline Comprehensive Ad ban and enforcement & & 255 & 550 & 528 & 11,348 \\
\hline High intensity tobacco control campaign & & 607 & 1,377 & 1,386 & 28,313 \\
\hline Strong health warnings & & 45 & 127 & 166 & 2,638 \\
\hline Strong youth access enforcement & & 0 & 9 & 92 & 489 \\
\hline Cessation treatment policies & & 407 & 1,109 & 1,375 & 22,877 \\
\hline \multicolumn{6}{|l|}{ Combined policy effects } \\
\hline All of the above & & 2,328 & 5,474 & 5,874 & 113,023 \\
\hline
\end{tabular}

years from 2011 through 2040, 19,008 deaths (12,818 males and 6,182 female) are averted by 2040 with the effects still growing.

While increasing taxes have the largest impact on smoking prevalence, comprehensive smoke-free air laws, a wellfunded campaign, and comprehensive treatment policies also have potent and more immediate effects on SADs. Smokefree air reduces smoking prevalence by $6.7 \%$ relative to the status quo scenario in 2011 . The effect increases to $7.9 \%$ by 2040. This policy is predicted to avert 1,544 deaths in 2040 , cumulating to 32,524 lives saved by 2040 . A well-funded campaign yields a 5.6\% reduction in 2011 smoking rates, increasing to about $7.7 \%$ by 2040 . With 1,386 fewer SADs in 2040 alone, a total of 28,313 lives are saved by 2040. Treatment policies are projected to reduce smoking rates by $4.5 \%$ by 2020 , growing to $6.5 \%$ and averting 1,275 SADs by 2040. Almost 23,000 deaths are averted by 2040 .

Strongly enforced youth access laws yield an immediate $0.5 \%$ relative reduction in smoking rates, but increase to $8 \%$ by 2040 . By 2040, youth access laws are projected to prevent 489 SADs.

Marketing restrictions and health warnings have smaller effects because these policies are already partially in place. A comprehensive marketing ban yields a $2.4 \%$ reduction in 2001 smoking prevalence, increasing to about $3.2 \%$ by 2040 . A total of 11,347 lives are saved by 2040. A stronger warning is projected to yield a $0.5 \%$ immediate reduction in smoking rates with a $1 \%$ reduction by 2040 and is projected to save 2,648 lives by 2040 .
The final scenario considers combining all the above policies. Smoking prevalence is initially projected to drop by $22 \%$ relative to status quo, increasing to almost $40 \%$ by 2040 . The model projects 5,874 fewer SADs in 2040. By 2040, a total of 113,023 deaths, 74,141 male and 38,882 female, are averted.

\section{Discussion}

We have applied population, smoking prevalence, and policy data for the Czech Republic and modified parameter values to the SimSmoke model. The model's projections are supported by validation in the CR and in countries with sufficient data to confirm predicted trends [11-15].

While some tobacco control policies have been implemented in recent years, the CR is still far from meeting the MPOWER targets. Using the SimSmoke model, we have projected that smoking prevalence can be decreased by as much as $22 \%$ on the short term, $35 \%$ by 20 years and almost $40 \%$ by 30 years. Because of the natural progression of tobaccorelated illnesses, reductions in smoking prevalence have a relatively small impact on SADs initially, but 5,873 deaths can be averted in 2040 alone. Without the complete set of MPOWER policies, 113,000 additional premature smoking related deaths will needlessly occur by 2040 .

The smoking projections are based on 2002 Czech smoking prevalence data, but cessation rates are based on other countries due to gaps in the CR data. Data on the distribution of quitting-smokers can be used to gauge the impact of 
tobacco control policies, and further validate the model. With data on policies, the impact of new policies can be evaluated and the model updated.

Relative smoking risks estimates are based primarily on US studies. Notably, the SADs estimates are conservative in that they exclude deaths due to second-hand smoke exposure.

Uncertainty surrounding the effects of each policy varies [3]. Many studies yield relatively consistent results for price. Many studies evaluate smoke-free air restrictions, but yield less consistent results. Less information is available on the impact of health warnings and treatment policies, or the interactive effects of policies.

SimSmoke results highlight the relative contribution of policies to reducing the tobacco health burden. Increasing cigarette taxes to $70 \%$ of price, stronger smoke-free air laws, a high intensity media campaign and a comprehensive treatment policy are each potent. When combined with strong youth access laws, stricter marketing bans and stronger warning labels, the smoking rate is projected to fall by $40 \%$ in relative terms and 113,000 deaths are averted by 2040.

\section{Key Points}

(i) The Czech Republic has a weak tobacco control record.

(ii) The Czech Republic has yet to ratify the WHO Framework Convention for Tobacco Control.

(iii) This paper shows that the effect of implementing policies consistent with the Czech Republic has a weak tobacco control record.

(iv) The smoking rate is projected to fall by $40 \%$ in relative terms and 113,000 deaths are averted by 2040 .

(v) Significant inroads to reducing smoking prevalence and premature mortality can be achieved through tax increases, a high intensity media campaign, a comprehensive cessation treatment program, strong health warnings, stronger smoke-free air laws and marketising bans, and well-enforced youth access laws.

\section{Conflict of Interests}

The authors have no conflict of interests to declare.

\section{Acknowledgments}

This is a deliverable within the PPACTE Project "Pricing Policies and Control of Tobacco in Europe" and is partly funded by the European Commission through FP7 HEALTH-F22009-223323. There were no restrictions placed on the material presented in this paper.

\section{References}

[1] M. Ezzati and A. D. Lopez, "Estimates of global mortality attributable to smoking in 2000," Lancet, vol. 362, no. 9387, pp. 847-852, 2003.
[2] US DHHS, Healthy People 2010, Centers for Disease Control, Office of Disease Prevention and Health Promotion, Atlanta, Ga, USA, 2000.

[3] D. T. Levy, J. Gitchell, and F. Chaloupka, "The effects of tobacco control policies on smoking rates: a tobacco control scorecard," Journal of Public Health Management and Practice, vol. 10, no. 4, pp. 338-353, 2004.

[4] WHO, Report on the Global Tobacco Epidemic, The MPOWER Package, World Health Organization, Geneva, Switzerland, 2008.

[5] World Health Organization, WHO Report on the Global Tobacco Epidemic: The MPOWER Package, World Health Organization, Geneva, Switzerland, 2008.

[6] Novinky.CZ, Č., 2010, http://www.novinky.cz/.

[7] L. Joossens and M. Raw, "The tobacco control scale 2010," in Proceedings of the 5th European Conference on Tobacco or Health, Association of European Cancer Leagues, Amsterdam, The Netherlands, 2011.

[8] J. B. Homer and G. B. Hirsch, "System dynamics modeling for public health: Background and opportunities," American Journal of Public Health, vol. 96, no. 3, pp. 452-458, 2006.

[9] D. T. Levy, J. E. Bauer, and H. R. Lee, "Simulation modeling and tobacco control: Creating more robust public health policies," American Journal of Public Health, vol. 96, no. 3, pp. 494-498, 2006.

[10] D. T. Levy, F. Chaloupka, J. Gitchell, D. Mendez, and K. E. Warner, "The use of simulation models for the surveillance, justification and understanding of tobacco control policies," Health Care Management Science, vol. 5, no. 2, pp. 113-120, 2002.

[11] D. T. Levy, S. Benjakul, H. Ross, and B. Ritthiphakdee, "The role of tobacco control policies in reducing smoking and deaths in a middle income nation: results from the Thailand SimSmoke simulation model," Tobacco Control, vol. 17, no. 1, pp. 53-59, 2008.

[12] D. T. Levy, S. I. Cho, and Y. M. Kim, S. Park, M. K. Suh, and S. Kam, "SimSmoke model evaluation of the effect of tobacco control policies in Korea: the unknown success story," American Journal of Public Health, vol. 100, no. 7, pp. 1267-1273, 2010.

[13] D. T. Levy, C. Tworek, E. J. Hahn, and R. E. Davis, “The Kentucky SimSmoke tobacco policy simulation model: Reaching Healthy People 2010 goals through policy change," Southern Medical Journal, vol. 101, no. 5, pp. 503-507, 2008.

[14] D. T. Levy, H. Ross, L. Powell, J. E. Bauer, and H. R. Lee, "The role of public policies in reducing smoking prevalence and deaths caused by smoking in Arizona: results from the Arizona tobacco policy simulation model," Journal of Public Health Management and Practice, vol. 13, no. 1, pp. 59-67, 2007.

[15] D. T. Levy, A. Hyland, C. Higbee, L. Remer, and C. Compton, "The role of public policies in reducing smoking prevalence in California. Results from the California Tobacco Policy Simulation Model," Health Policy, vol. 82, no. 2, pp. 153-166, 2007.

[16] CIA, World Fact Book, 2011.

[17] R. West, M. E. DiMarino, J. Gitchell, and A. McNeill, "Impact of UK policy initiatives on use of medicines to aid smoking cessation," Tobacco Control, vol. 14, no. 3, pp. 166-171, 2005.

[18] J. Kaper, E. J. Wagena, M. C. Willemsen, and C. P. Van Schayck, "A randomized controlled trial to assess the effects of reimbursing the costs of smoking cessation therapy on sustained abstinence," Addiction, vol. 101, no. 11, pp. 1656-1661, 2006. 
[19] US DHHS, "The Health Benefits of Smoking Cessation: a report of the Surgeon General," Atlanta, Ga, USA, US Department of Health and Human Services, Public Health Service, Centers for Disease Control, Office on Smoking and Health, 1990.

[20] J. R. Hughes, J. Keely, and S. Naud, "Shape of the relapse curve and long-term abstinence among untreated smokers," Addiction, vol. 99, no. 1, pp. 29-38, 2004.

[21] National Cancer Institute, "Cigarette smoking behavior in the United States," in Changes in Cigarette-Related Disease Risks and Their Implication for Prevention and Control, Smoking and Tobacco Control Monograph 8, D. Burns, L. Lee, and L. Shen, Eds., pp. 13-112, National Cancer Institute, National Institutes of Health, Bethesda, Md, USA, 1997.

[22] R. Doll, R. Peto, J. Boreham, and I. Sutherland, "Mortality in relation to smoking: 50 Years' observations on male British doctors," British Medical Journal, vol. 328, no. 7455, pp. 15191528, 2004.

[23] F. Perlman and M. Bobak, "Socioeconomic and Behavioral Determinants of Mortality in Posttransition Russia: A Prospective Population Study," Annals of Epidemiology, vol. 18, no. 2, pp. 92-100, 2008.

[24] Economic Intelligence Unit, Worldwide cost of living, 2010.

[25] OECD, OECD Data, 2011.

[26] F. J. Chaloupka, T. Hu, K. E. Warner, R. Jacobs, and A. Yurekli, "The taxation of tobacco products," in Tobacco Control in Developing Countries, P. Jha and F. Chaloupka, Eds., pp. 237272, Oxford University Press, 2000.

[27] R. Hanewinkel, C. Radden, and T. Rosenkranz, "Price increase causes fewer sales of factory-made cigarettes and higher sales of cheaper loose tobacco in Germany," Health Economics, vol. 17, no. 6, pp. 683-693, 2008.

[28] D. T. Levy and K. Friend, "A framework for evaluating and improving clean indoor air laws," Journal of Public Health Management and Practice, vol. 7, no. 5, pp. 87-96, 2001.

[29] E. Blecher, "The impact of tobacco advertising bans on consumption in developing countries," Journal of Health Economics, vol. 27, no. 4, pp. 930-942, 2008.

[30] D. Hammond, G. T. Fong, R. Borland, K. M. Cummings, A. McNeill, and P. Driezen, "Text and graphic warnings on cigarette packages. Findings from the International Tobacco Control Four Country Study," American Journal of Preventive Medicine, vol. 32, no. 3, pp. 202-209, 2007.

[31] M. C. Willemsen, "The new EU cigarette health warnings benefit smokers who want to quit the habit: Results from the Dutch Continuous Survey of Smoking Habits," European Journal of Public Health, vol. 15, no. 4, pp. 389-392, 2005.

[32] M. Bala, L. Strzeszynski, and K. Cahill, "Mass media interventions for smoking cessation in adults," Cochrane Database of Systematic Reviews, no. 1, Article ID CD004704, 2008.

[33] D. T. Levy and K. B. Friend, "A simulation model of tobacco youth access policies," Journal of Health Politics, Policy and Law, vol. 25, no. 6, pp. 1023-1050, 2000.

[34] T. Baška, H. Sovinová, A. Németh et al., "Findings from the Global Youth Tobacco Survey (GYTS) in Czech Republic, Hungary, Poland and Slovakia-smoking initiation, prevalence of tobacco use and cessation," Sozial- und Praventivmedizin, vol. 51, no. 2, pp. 110-116, 2006.

[35] H. Sovinová, L. Csemy, C. W. Warren, J. Lee, and V. Lea, "Changes in tobacco use among 13-15-year-olds in the czech republic_-2002 and 2007," Central European Journal of Public Health, vol. 16, no. 4, pp. 199-204, 2008.
[36] D. B. Abrams, A. L. Graham, D. T. Levy, P. L. Mabry, and C. T. Orleans, "Boosting population quits through evidence-based cessation treatment and policy," American Journal of Preventive Medicine, vol. 38, no. 3, pp. S351-S363, 2010.

[37] S. Shiffman, J. Gitchell, J. M. Pinney, S. L. Burton, K. E. Kemper, and E. A. Lara, "Public health benefit of over-thecounter nicotine medications," Tobacco Control, vol. 6, no. 4, pp. 306-310, 1997.

[38] A. Hyland, H. Rezaishiraz, G. Giovino, J. E. Bauer, and K. M. Cummings, "Over-the-counter availability of nicotine replacement therapy and smoking cessation," Nicotine and Tobacco Research, vol. 7, no. 4, pp. 547-556, 2005.

[39] E. Kralikova, "Increasing the level of information about smoking cessation in Prague," Project of the City Hall Prague, 2007.

[40] H. Sovinová, P. Sadílek, and L. Csemy, "Vývoj Prevalence Kư̌áctví V Dospělé Populaci České Republiky (1991-2009),” Development Of The Prevalence Of Smoking In The Adult Population Of The Czech Republic-Part I, 2011. 


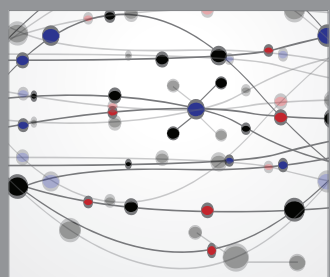

The Scientific World Journal
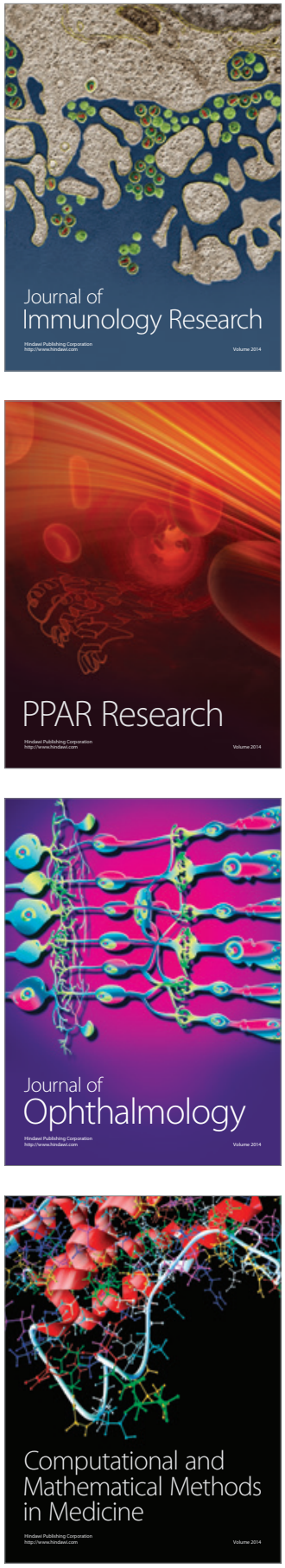

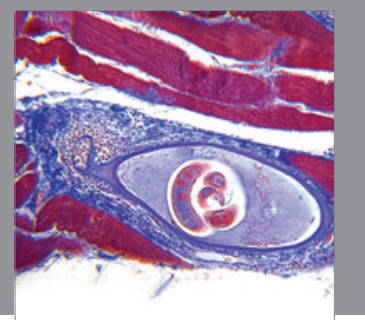

Gastroenterology

Research and Practice
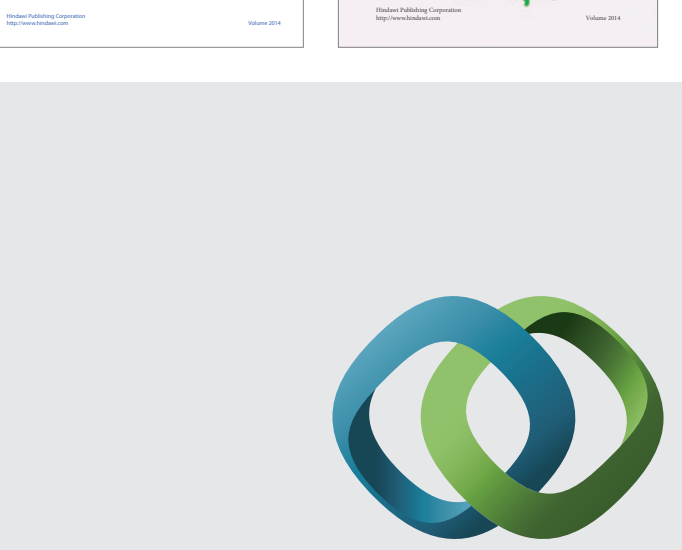

\section{Hindawi}

Submit your manuscripts at

http://www.hindawi.com
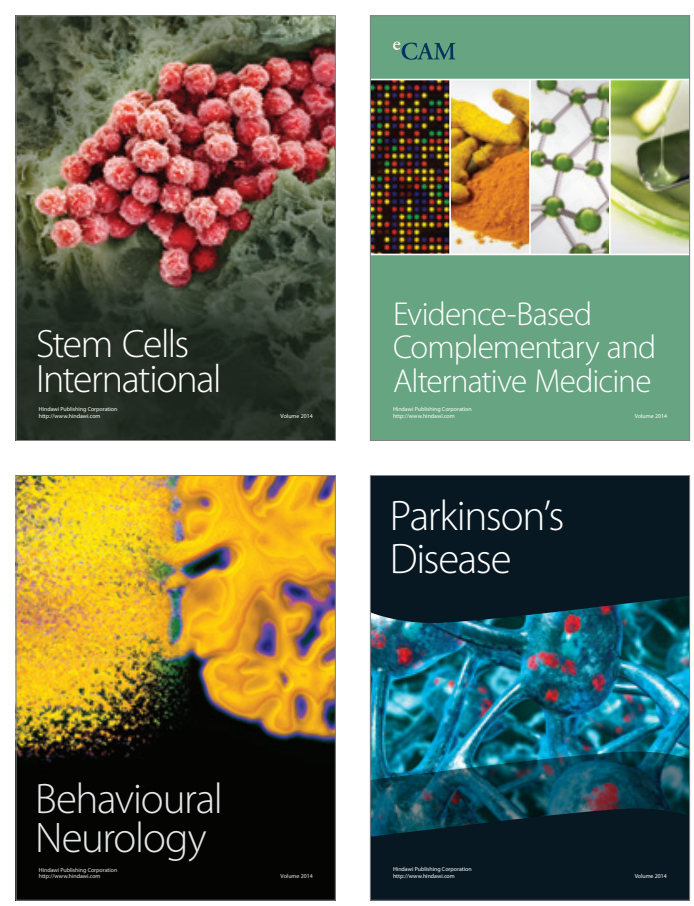

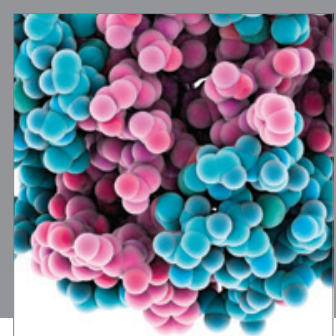

Journal of
Diabetes Research

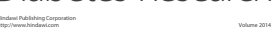

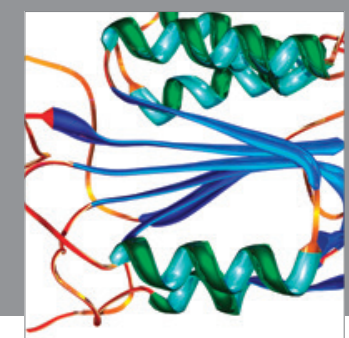

Disease Markers
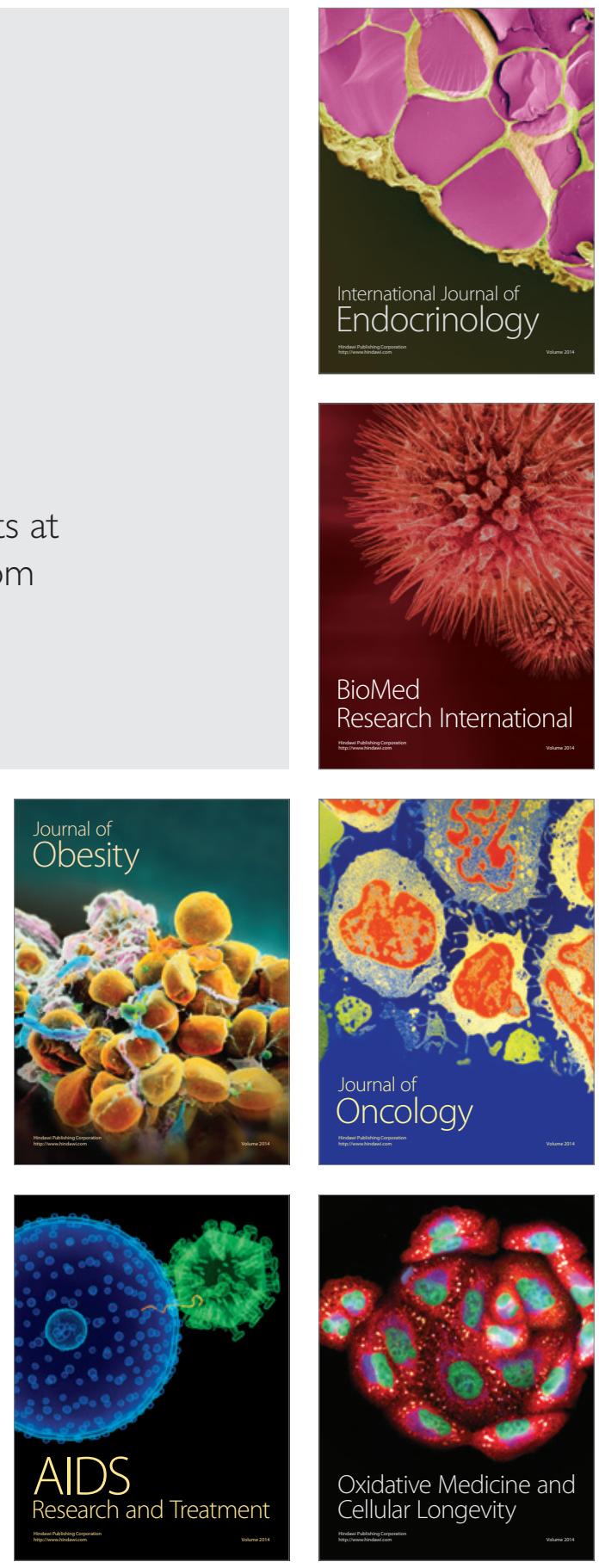